\title{
LEITURA CALEIDOSCÓPICA DA NATUREZA: O ENCONTRO DE BARROS E MANCUSO*
}

\author{
Kaleidoscopic reading of nature: the meeting of Barros and Mancuso
}

\author{
Nincia Borges Teixeira* \\ Universidade Estadual do Centro-Oeste
}

Resumo: As mais diversas manifestações artísticas, guardadas suas especificidades, permitem dialogicidades múltiplas consubstanciadas em proximidades e diferenças. Olhares plurais, muitas vezes sobre os mesmos temas, possibilitam leituras diversas e pertinentes que se ampliam e se iluminam à medida que se estabelecem os confrontos. Assim, a pesquisa privilegia a literatura como uma das instâncias de reflexão e, a partir desse centro de interesse, focaliza as relações que se podem estabelecer com outras linguagens. Nesse caso, promove uma aproximação entre poesia e ilustração, a partir de uma abordagem comparativa entre uma poesia de Manoel de Barros e uma ilustração da artista contemporânea Brunna Mancuso. Utilizamos como base teórica fundamental textos de crítica de arte e literatura que possibilitaram uma compreensão acerca desse encontro. Consideramos as diversas relações entre diferentes gêneros artísticos e, por meio de uma perspectiva metodológica comparativista, foram feitos levantamentos das similaridades entre as duas obras expressas em linguagens diferentes e períodos distintos.

Palavras-chave: Manoel de Barros. Poesia. Brunna Mancuso. Ilustração. Confluência.

Abstract: The most diverse artistic manifestations, preserving their specificities, allow multiple dialogicizes embodied in proximity and differences. Plural looks, often on the same themes, enable diverse and pertinent readings that widen and brighten as confrontations are established. Thus, research privileges literature as one of the instances of reflection and, from this center of interest, focuses on relationships that can be established with other languages. In this case, it

Esta obra está licenciada sob uma Creative Commons - Atribuição 4.0

\footnotetext{
* Nota de redundância:

Em meados de 2020, a autora deste artigo foi informada que no mesmo ano teve o texto "Leitura caleidoscópica da natureza: o encontro de Barros e Mancuso" tramitado e publicado simultaneamente também na Revista Terceira Margem. A editoria investigou o assunto seguindo as diretrizes do Comitê de Ética em Publicações (COPE) sobre publicação duplicada e, com base nos vários critérios fornecidos pelas diretrizes da COPE, a comissão editorial determinou a publicação deste aviso de publicação redundante. A comissão reconhece a pronta cooperação da autora na abordagem deste assunto.

* Doutora em Letras pela Universidade Estadual Paulista Júlio de Mesquita Filho (2005), Mestre em Letras pela Universidade Estadual de Londrina. É Professora Associada da Universidade Estadual do Centro-Oeste (UNICENTRO). Professora nos cursos de Letras e Comunicação Social. Coordenadora do Programa Mestrado em Letras da UNICENTRO. E-mail: ninciaborgesteixeira@yahoo.com.br.
}

iD https://orcid.org/0000-0002-5719-7364

Anu. Lit., Florianópolis, v. 23, n. 2, p. 34-45, 2018. ISSNe 2175-7917 
promotes an approximation between poetry and illustration, based on a comparative approach between a poem by Manoel de Barros and an illustration by the contemporary artist Brunna Mancuso. We use as fundamental theoretical basis texts of criticism of art and literature that made possible an understanding about this encounter. We considered the various relationships between different artistic genres and, through a comparative methodological perspective, surveys of the similarities between the two works expressed in different.

Keywords: Manoel de Barros. Poetry. Brunna Mancuso. Illustration. Confluence.

Recebido em: 14/05/2018

Aceito em: 26/08/2018

Por entre as linhas incautas da leitura ideia insidiosa se insinua, como se sugerisse um outro texto mais vivo, extremo, e verdadeiro (BRITTO, 1997, p. 11).

\section{Primeiros olhares: Literatura em diálogo com outras linguagens}

Atualmente, os Estudos de Literatura têm procurado aproximar o diálogo crítico e epistemológico entre a Literatura e as mais diferentes áreas do conhecimento humano. Tal fato já se tornou, inclusive, a principal premissa da Literatura Comparada, que há muito deixou de fazer análises simplesmente binárias entre as diferentes literaturas, mas iniciou uma saudável tradição de crítica na perspectiva de interligar a Literatura aos Estudos Culturais. As diferenciadas formas de expressões e linguagens, na pós-modernidade, sofrem os mais variados processos de hibridação, dessa forma analisar o papel da arte na sociedade de consumo e, principalmente, as relações que se estabelecem entre a literatura e outras formas de expressão torna-se tarefa essencial. O diálogo entre literatura e outras áreas sempre despertou a atenção dos estudiosos dessas linguagens, convocando-os a investigar as bases teóricas em que essas relações se estabelecem ou a examinar, mediante exercícios interpretativos de diversos tipos de textos que se atualizam nas manifestações artísticas.

Adentrar no campo da Literatura Comparada é "[...] colaborar para o entendimento do Outro" (CARVALHAL,1997, p.8) e, nesse processo, a compreensão do material literário. Para Sandra Nitrini (1997), comparar faz parte da estrutura do pensamento do homem e da organização da cultura, assim valer-se da comparação é hábito generalizado em diferentes áreas do saber humano e mesmo na linguagem corrente, onde o exemplo dos provérbios ilustra a frequência de emprego do recurso. A literatura comparada analisa não pelo procedimento em si, mas porque, como recurso analítico e interpretativo, esse método possibilita a esse tipo de estudo literário uma exploração adequada de seus campos de trabalho e o alcance dos objetivos a que se propõe. Em síntese, a comparação, mesmo nos estudos comparados, é um meio, não um fim. Mas, embora ela não seja exclusiva da literatura comparada, não podendo, então, por si só defini-la será seu emprego sistemático que irá caracterizar sua atuação.

Todo texto "literário" possui parentes "não-literários" que lhe são mais próximos do que os outros textos do cânone. Essa constatação não é original, evidentemente: basta citar um 
crítico como Northrop Frye (2000) para quem o universo literário se desenvolveu num universo verbal, o que, todavia, o estudioso da literatura muitas vezes prefere ignorar, fascinado apenas pela ponta do iceberg, que passa a ser considerado o único "objeto" dos estudos literários.

A partir da década de 1970, anunciou-se um processo de transformação nos estudos comparados, orientado por questões ligadas à identidade nacional e cultural. Tanto centros hegemônicos, em princípio na América do Norte e na Europa Ocidental, como periféricos, participaram deste processo: lá, as minorias organizadas; aqui, a preocupação em analisar as questões literárias a partir do lugar de origem do pesquisador. Este processo foi sustentado por correntes como o desconstrutivismo, a nova história e os chamados estudos culturais e póscoloniais. A transformação propriamente dita consiste, conforme Coutinho (1996, p.67), "na passagem de um discurso coeso e unânime, com forte propensão universalizante, para outro plural e descentrado, situado historicamente, e consciente das diferenças que identificam cada corpus literário envolvido no processo de comparação".

Ganha força a teoria de Jacques Derrida (1995), segundo a qual um mesmo enunciado pode ser considerado literário ou não, conforme a situação ou a convenção. É que o signo da literariedade não é uma propriedade intrínseca deste ou daquele evento literário. Contudo, Derrida também alertou que, às vezes, é difícil discernir um texto filosófico de um texto poético ou literário. Para poder lidar com o universo verbal e com essa proliferação vertiginosa de mensagens que circundam, contaminam, enriquecem e subvertem o antigo artefato literário (a ponta do iceberg), o estudioso da literatura estreitou o diálogo com as outras áreas das ciências humanas (filosofia, história, antropologia, sociologia etc.). Esse procedimento caracteriza certa linha de estudos que, a partir dos anos 1980, vem se disseminando pelas Américas sob a denominação de estudos culturais.

Para os Estudos Culturais, a literatura mantém um constante diálogo com outras disciplinas, o que permite a convivência de diversos conceitos teórico-metodológicos na análise dos objetos literários, ampliando a visão para além da ordem textual. Dessa forma, atinge dimensões de ordem cultural de tal forma que o objeto literário assume funções de objeto teórico, constituindo-se como um produtor de saber e revelando os efeitos desconstrutores das relações interculturais. Estas trazem à tona discussões sobre o popular, a memória cultural e a maneira como a história é construída.

Portanto, ao analisar sob a perspectiva dos Estudos Culturais, as obras de arte não possuem significados fixo e determinado. Ao contrário, é precisamente no caráter polissêmico da obra que reside seu valor. O significado de uma obra representa uma série de interpretações. A arte, como diz Ernest Fischer (1983), jamais se limitaria a mera descrição da realidade social. Ao contrário, é função do artista interpretar essa realidade através de sua visão do mundo e de manifestar suas concepções políticas e ideológicas.

A mudança do foco literário para o cultural foi ocasionada por uma "virada sociológica" (MILNER, 1996, p. 11). Se o conceito de cultura postulado por Leavis enfatizava as categorias de (alta) arte e estética, para Raymond Williams, o conceito de cultura é mais elástico. Ao deslocar a noção de cultura das definições de artes e humanidades para as de ciências humanas

Anu. Lit., Florianópolis, v. 23, n. 2, p. 34-45, 2018. ISSNe 2175-7917 
e sociais, os estudos culturais "tenderiam a ver o valor cultural como socialmente construído", enquanto "os estudos literários tradicionais definiam a literatura como uma categoria estética atemporal” (MILNER, 1996, p.11). Nessa nova visão, o foco da análise incide nos textos culturais e indicadores sociológicos, como a classe social. Num primeiro momento, o texto literário canonizado, inserido em uma visão leavisiana de literatura, é descartado como objeto de estudo.

As relações entre a literatura e as outras linguagens não constituem um fenômeno recente. Há muito que o texto literário vem estabelecendo elos produtivos com a música, a fotografia, o teatro, as artes plásticas, o cinema, entre tantas outras. Tampouco podemos classificar como novidade o fato de a literatura ter estabelecido contatos com os veículos de comunicação de massa, como passa a acontecer sobretudo a partir da segunda metade do século XX. O que sobressai, no entanto, a partir do cruzamento e das relações entre o texto literário, as demais artes e a cultura das mídias parece apontar para novos modos de representação do mundo, bem como para uma nova posição do sujeito frente a uma sociedade saturada de imagens e pautada pela velocidade da informação em fragmentos. Na intersecção das artes e das mídias, a escritura torna-se um lugar de constantes mutações. Formas mistas clamam pela atividade cooperativa do leitor, do ouvinte e do espectador, bem como de um leitor com atributos de crítico de arte, de ouvinte e de espectador.

O ser humano é essencialmente um ser de linguagem. De acordo com Oliveira (1996), as ciências, as artes, a psicanálise e os meios de comunicação - detentores de códigos particulares - transformaram o mundo em uma grande massa de signos. Essa abundância de linguagens acabou por forçar uma diluição de suas fronteiras, mas jamais a demarcação desses territórios foi tão imperceptível e irrelevante quanto hoje, quando, por exemplo, buscamos estabelecer o relacionamento entre duas formas de manifestações artísticas.

De acordo com Diniz (2007), Apesar da migração de signos e recursos de um campo para outro se constituir em um fenômeno que atingiu todo o campo das artes, jamais se registrou como agora com tanta frequência e intensidade esse fenômeno. $\mathrm{O}$ surgimento dos meios de comunicação trouxe profundas transformações, ampliando potencialidades sensitivas e reconfigurando nossos campos perceptivos. Esse entrelaçamento dos signos promove significativas alterações nas formas de sentir, pensar, ver e apreender o mundo, enfim, de traduzi-lo em palavras e imagens.

Os diversos processos de reprodução que a técnica coloca a nosso dispor, os objetos estéticos, antes restritos ao conhecimento e à contemplação de poucos, tornaram-se, a partir de então, acessíveis a um número cada vez maior de pessoas. Sendo os meios tecnológicos dotados de linguagens diversas das esteticamente consagradas, seu aparecimento acabou por promover uma reconfiguração, tanto do modo de recepção quanto do próprio fazer artístico, de sua forma de produção e do papel que a arte hoje desempenha socialmente, frente a um mundo dominado pela técnica, que demanda novas respostas a seus anseios, angústias e questionamentos. Em seu importante ensaio "A obra de arte na era de sua reprodutibilidade técnica”, Benjamin (1982) já chamava a atenção para o fato de que, alterado o modo de percepção da realidade pelo

Anu. Lit., Florianópolis, v. 23, n. 2, p. 34-45, 2018. ISSNe 2175-7917 
surgimento da fotografia e do cinema, o campo estético viu-se fatalmente afetado em seus domínios.

Ao se dotar de linguagens características, os meios artísticos não apenas tomaram de empréstimo elementos inerentes a outros campos, mas logo estabeleceram um rico intercâmbio com as diversas formas de expressão artística emprestando-lhes, inclusive, muitas de suas nuanças técnicas.

De acordo com Compagnon (2003), para se estudar literatura é necessário que se realize a distinção entre senso comum e literatura. $\mathrm{O}$ primeiro aspecto refere-se à existência de uma obra, escrita por alguém, em uma determinada época e espaço, contendo um enredo passível de múltiplas interpretações de seus leitores. O segundo refere-se a uma espécie de deontologia da pesquisa literária, na busca de compreender melhor os aspectos da obra em seus processos dos pontos de vista: autoral, do leitor, do estilo da escrita da obra, das temáticas abordadas, na compreensão do texto literário como manifestação exemplar da poética no uso das palavras e composição de textos em uma dada língua, entre outras possibilidades de relação dos textos da literatura com o mundo.

Néstor García Canclini (1990) defende a necessidade da adoção de um enfoque chamado de híbrido, pois resulta da combinação da antropologia com a sociologia, da arte com os estudos das comunicações. O autor, ao analisar as formas de hibridismo na América Latina no final do século XX, que foram geradas por contradições decorrentes do convívio social urbano e do contexto internacional, conclui que todas as culturas são de fronteira e que as artes, em virtude do fenômeno da desterritorialização, articulam-se em relação umas com as outras, sendo-lhes possível, com isso, ampliar seu potencial de comunicação e conhecimento. Ainda que indiretamente, as práticas culturais passam a ocupar um lugar proeminente no processo de desenvolvimento político, uma vez que, quando se fecham ou se enrijecem as vias políticosociais, essas práticas se constituem em vias de expressão simbólica, com ação e atuação efetivas. Trata-se, portanto, de verificar "quais são as consequências políticas que decorrem da passagem de uma concepção vertical e bipolar das relações sociopolíticas para outra descentralizada e multideterminada" (CANCLINI, 1990, p. 345).

A ampliação do conceito de literatura revela-se não somente uma exigência fundamental para a compreensão de sua função contemporânea, como também uma complexa relação com os meios de comunicação de massa. Hoje, o universo da literatura não se limita mais à página impressa do livro, mas é estendido às crônicas de jornal, aos roteiros de cinema, rádio e televisão, assim como aos textos publicitários. Isso porque, a evolução da produção de mensagens acompanha a atividade de interpretação e práticas de consumo, caracterizando a sedimentação de um capital cultural próprio do leitor das mensagens da comunicação de massa, uma vez que é ele que finaliza o circuito comunicativo.

Um texto, portanto, não está pronto é construído junto ao seu destinatário, que interpreta e assume uma atitude responsiva ativa. Todavia, a interpretação depende da caminhada leitora que se tem, já que um texto dialoga com outros textos. O leitor só irá notar a presença do diálogo entre os textos se tiver leituras anteriores, que fornecem subsídios na identificação dos 
cruzamentos dos textos, caso contrário podem não notar.

A reflexão a seguir aborda o diálogo entre a obra de Manoel de Barros "Na Fazenda" e a ilustração de Brunna Mancuso, marcando o encontro entre a literatura e as artes plásticas.

\section{Manoel de Barros e Brunna Mancuso: entre o sonho e a racionalidade}

Manoel de Barros nasceu na cidade de Cuiabá, Mato Grosso. Considerado como um dos maiores poetas brasileiros, sua obra está cronologicamente vinculada à Geração Modernista de 1945, pois estreou em 1937 com o livro Poemas Concebidos sem Pecado.

Para Maria Heloísa Martins Dias (2009, p. 01),

a poesia de Manoel de Barros desperta a atenção do leitor não tanto pela temática que traz em sua linguagem quanto, principalmente, pela forma inusitada como (re)configura essa matéria enquanto dizer. Falar sobre o mundo e criar um meio singular que dê corpo a essa fala são gestos simultâneos - projeto em afinidade com uma tradição poética que faz da palavra sujeito e objeto, uma autoconsciência onde se alojam criação e leitura, espírito crítico e ludicidade.

Na poesia de Manuel de Barros, o leitor é convidado a viajar pela imaginação e pelas linhas inventadas na composição singular, quase desconsiderando as letras. A construção de sentido é feita pelas pistas deixadas nos textos, por meio da criação de imagens, pela sugestão de suas memórias, que são inventadas, indiciando, a partir desse pressuposto, uma estratégia de leitura, um caminho a ser percorrido por seu leitor.

Sua obra resulta num trabalho caleidoscópico, de difícil classificação. De acordo Ênio Silveira (2001), o resultado de seu trabalho é multifacetado, varia do telúrico ao surrealista, apresenta uma precisão descritiva, assim como surpreendentes metáforas. Barros utiliza, quase sempre, motivos que se ligam à natureza de forma que dela sobrevêm tanto elementos identitários quanto metaliterários. Renato Suttana assevera que a partir das imagens que surgem nos seus poemas, ele passa a "traçar relações entre o espaço das coisas e o espaço das palavras" (SUTTANA, 1995, p. 5). Um dos maiores paradoxos que a poesia de Manoel de Barros carrega em seu bojo, conforme aponta Dias (2009), é que nessa aparência de simplicidade ou pequenez que dela desponta, seja em versos, em títulos dos poemas e obras, a apologia do pequeno defendida por Manoel de Barros deve ser colocada sob suspeita. Essa vocação para o despojamento se revela pois a busca do poeta é por "tudo que use o abandono por dentro e por fora." (BARROS, 2000, p.7), como confessa no "Pretexto" ao Livro sobre nada.

Alberto Pucheu (2015) nos alerta que o trabalho de desobediência do poeta, entendido enquanto "um aparelho de ser inútil", pelo fazer da escrita resultante de um dom, ocorre na construção material da frase desse que, por não se adequar, precisa escapar, mesmo que andando de costas.

A pesquisa parte dos versos manoelinos: "Não tenho conexões com a realidade. Poderoso para mim não é aquele que descobre ouro. Para mim poderoso é aquele que descobre as insignificâncias do mundo e as nossas". O que se busca aqui, pois, não é descobrir ouro, mas 
promover conexões entre o texto verbal e do não verbal, o diálogo entre as artes de Manoel de Barros e a ilustradora Bruna Mancuso.

A "irrealidade" dos versos do poeta pantaneiro se transforma para o leitor em imagens, isto é, na representação de realidades que podem ser experimentadas. Sua poesia se assemelha muito com elementos que são próprios da pintura, o que a torna algo quase palpável, isso causa no leitor a sensação de que o abismo existente entre o que ele é e o que deseja é relativamente diminuído.

A relevância da leitura e da interpretação, tanto do texto quanto da imagem, contribui para o diálogo entre as diferentes artes. Evidentemente que, para tal recepção consideram-se as evidências, pistas deixadas pelos autores, que, se confrontadas, revelam encantamento e inquietam: foram propositais ou apenas coincidências. Mario Praz afirma que "[...] congregar as belezas comuns da poesia, da pintura [...]; mostrar-lhe as analogias; explicar como o poeta e o pintor representaram a mesma imagem; surpreender os emblemas fugitivos de sua expressão; examinar se não haveria alguma similitude entre esses emblemas, etc., eis o que resta fazer (PRAZ, 1982, p. 23). Esse movimento numa perspectiva de possibilidades de leitura e não como imposição de definições.

Brunna Mancuso é ilustradora e designer, em sua obra utiliza vários materiais como guache, aquarela e nanquim. Para a ilustradora, a arte visual é uma forma (com ressalvas culturais) bastante universal de dizer o que está se sentindo. Ao ser entrevistada, Mancuso afirma que não faz arte e que tem problemas em se auto intitular como artista:

O que eu faço, que pode ser mais próximo de arte, que são os murais ou as exposições, não me dão dinheiro quase nenhum. O que sempre me sustentou é meu trabalho como designer gráfico, o que eu gosto muito de fazer e o que inclusive me faz crer que não pretendo trabalhar como artista. Adoro integrar essa posição de artista com designer e acho que isso enriquece muito meu trabalho como designer e ilustradora, então acho que vou continuar seguindo essa linha (MANCUSO, 2018, on-line).

As ilustrações, ao contrário das artes plásticas, são caracterizadas como representação, ou interpretação, de um conteúdo verbal. Segundo Julia Lima Carvalho (2014), é mais que uma expressão plástica, pois tem a capacidade de simbolizar, ao trazer para o presente da imagem os sentidos e sentimentos, é a possibilidade de tornar real o imaginado. Toda ilustração parte do real, ou ao menos do texto, para ser interpretada, e é o espaço para o leitor se projetar minimamente naquele espaço. Para Carvalho (2014), realidade e imaginação estão na própria definição de representação. Ao mesmo tempo em que faz referência a um objeto, ou realidade fora dela, também cria algo de novo. As representações são sempre aproximações condicionadas pelo nosso olhar, e o olhar e o interpretar dependem da experiência pessoal, social e cultural.

Brunna Mancuso desenvolve ilustrações em aquarela com texturas, padronagens ou finalizadas digitalmente. Sua obra parte de formas orgânicas e geométricas com traços inspirados na força feminina, na fauna e na flora. Para a artista, sua arte se baseia em um processo constante de construção e desconstrução, no qual ela destaca os pequenos detalhes. A 
representação da mulher está sempre presente em seu trabalho, como uma forma de se posicionar, ela representa uma mulher complexa, moderna e dona de si, que se sente confortável consigo mesma.

O diálogo que ocorre entre a poesia de Manoel de Barros e as ilustrações de Mancuso parte da ficção que expressa uma verdade que só pode ser manifestada disfarçadamente, e que se apresentam através dos desenhos verbais e poesia em desenhos. Isso se torna relevante, pois tanto a escrita e as ilustrações desses artistas nos inquietam abrindo a possibilidade de uma libertação do sentido, não importando o caráter "lógico" ou "real" de uma observação que traça a linha fronteiriça entre a verdade histórica e a verdade poética. Há, portanto, uma libertação de aprisionamento do sentido pré-estabelecido, consequente de uma leitura baseada no pensamento lógico e científico.

Na poesia "Na Fazenda":

Na Fazenda

Barulhinho vermelho de cajus e o riacho passando nos fundos do quintal... Dali se escutavam os ventos com a boca como um dia ser árvore.

Eu era lutador de jacaré. As árvores falavam. Bugre Teotônio bebia marandovás.

Víamos por toda parte cabelos misgalhadinhos de borboletas...

Abriu-se uma pedra certa vez: os musgos eram frescos...

As plantas me ensinavam de chão. Fui aprendendo com o corpo.

Hoje sofro de gorjeios nos lugares puídos de mim. Sofro de árvores. (BARROS, 2010, p. 115)

Manuel de Barros registra sobre o fazer parte de uma árvore e ser escolhido para ser um passarinho, o se transformar em uma árvore, é uma metáfora que se repete por toda sua obra, aponta para o fato que o ser humano deveria abandonar por completo os estado de sociedade e cultura para viver unicamente no estado de natureza. Na ótica de Barros, por meio da cultura, o homem se afasta de um estado de inocência, assim no verso: "As plantas me ensinavam sobre o chão" (BARROS, 2010, p. 115) ocorre a volta a esse estágio primordial por meio da poesia, o espaço, pois, colabora para o movimento do eu lírico cujo nascedouro é a natureza e todas as relações que emanam de seu universo: terra, fauna, flora.

Barros retrata o homem pantaneiro - "Bugre Teotônio bebia marandovás. Víamos por toda parte cabelos misgalhadinhos de borboletas" (BARROS, 2010, p. 115) - que vivencia uma cultura que é moldada pela natureza que a tudo determina. A natureza, então, não é apenas um aparato da língua, mas tem valor fundamental: a metáfora está muito além do que conhecemos como tempo, lugar e sentimento. Poeta da natureza da palavra, Manoel de Barros faz uma recriação poética do espaço do Pantanal ao buscar na raiz das coisas sua constituição. O espaço se dá, o se constrói, a partir do momento em que a voz do poeta vai nominando tudo que concerne ao mundo pré-concebido. (LIMA, 2008, p. 12). O universo predominante em Manoel de Barros é do homem que vive em constante relação com a água, terra, ar, natureza animal, natureza vegetal, embora a predominância para as poesias destacadas seja o universo água. Conforme Lucy Ferreira Azevedo (2015, p. 19): 
É nesta perspectiva do homem ligado à natureza que o autor constrói sua poética, vai na contramão da lírica tradicional, e reflete um comportamento identitário a partir da sensibilidade nascida da geografia, da história de um povo de um determinado local do país, que é o Pantanal, especial por suas peculiaridades; agreste por sua vivência e particular pelo contato inalienável com a natureza.

Figura 1: Na ilustração de Mancuso:

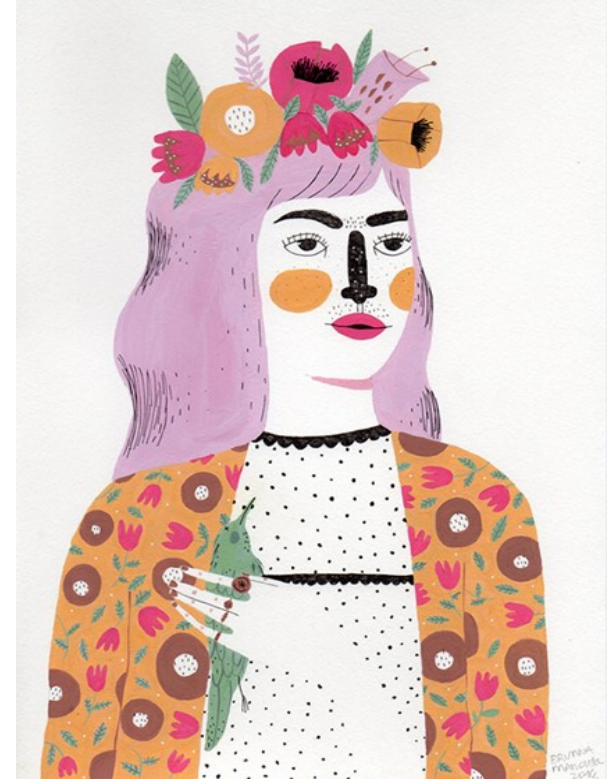

Fonte: MANCUSO, Bruna. As ilustrações de Brunna Mancuso mostram a força feminina com formas geométricas e botânica: Entrevista. $2016^{1}$.

A mulher é esboçada como um ser ligado a aspectos da natureza (flores e pássaro). A ilustradora utiliza-se de traços simples. Há uma variedade cromática, com predominância das cores quentes, entre elas os vermelhos e lilases, com toques de marrom, branco e preto. A luz transmite equilíbrio entre claros e escuros, passando a sensação de volume, proximidade e profundidade. No desenho, as cores das flores são mais carregadas, já na mão da personagem, que simboliza o universo, percebemos um pássaro. Notamos um grande contraste localizado no centro da tela, gerado pelo branco do vestido e o colorido dos cabelos e das flores no alto da cabeça, bem como ave verde que a personagem segura, este grande contraste faz com que nosso olhar focalize o centro da pintura.

Mancuso lança mão de metáforas visuais, Black (1962) destaca que a metáfora é basicamente uma questão de pensamento e não simplesmente uma figura de linguagem. Ele afirma que metáforas são fundamentalmente de caráter conceitual e podem ser desenvolvidas em qualquer mídia. A ilustradora desenha um pássaro que, segundo Chevalier e Gheerbrant (1998), simboliza a alma e a liberdade, além disso aves simbolizam a personalidade de um eu lírico sonhador. As flores representam fertilidade a perfeição espiritual e o ciclo vital. Quando estão abertas refletem tudo o que é passivo e feminino e tudo o que esteja ligado à beleza e ao

\footnotetext{
${ }^{1}$ Disponível em: http://www.zupi.com.br/ilustracoes-de-brunna-mancuso-mostram-forca-feminina-com-formasgeometricas-e-botanica/. Acesso em: 07/09/2018.
}

Anu. Lit., Florianópolis, v. 23, n. 2, p. 34-45, 2018. ISSNe 2175-7917 
espírito. Imagens que estão associadas à psicologia da mulher em diferentes fases de sua vida, da puberdade à velhice, que, por sua vez, representam os aspectos da natureza intrínseca do feminino. A cor violeta dos cabelos da mulher representada na ilustração equivale ao equilíbrio entre a matéria e o espírito, aos sentidos e a razão (CHEVALIER; GHEERBRANT, 1998). Violeta é também a cor que simboliza as ações refletidas. Esta força vital vem da junção das cores, que cria o violeta, equilibrando o vermelho, cor que representa tudo que é relativo ao terreno, e o azul, que representa o celeste.

Assim, a mulher na obra de Mancuso se constrói na relação com a natureza animal e vegetal, ao mesmo tempo que se liga ao aspecto terreno possui laços com o espiritual. Os símbolos utilizados voltam-se para a construção da figura da grande mãe, da grande deusa, o arquétipo feminino que se assume no contexto de uma narrativa ou de epopeia mitológica, para Woolger (1994, p. 15-16):

o que vale dizer, fontes derradeiras daqueles padrões emocionais de nossos pensamentos, sentimentos, instintos e comportamento que poderíamos chamar de 'femininos' na acepção mais ampla da palavra. Tudo o que pensamos com criatividade e inspiração, tudo o que acalentamos, que amamentamos, que gostamos, toda a paixão, desejo e sexualidade, tudo o que nos impele à união, à coesão social, à comunhão e à proximidade humana, todas as alianças e fusões, e também todos os impulsos de absorver, destruir, reproduzir e duplicar, pertencem ao arquétipo do feminino.

O diálogo que se estabelece entre Barros e Mancuso parte do elemento natureza projetado na arte de e na cultura, dinamizando a natureza do homem do pantanal e da natureza arquetípica feminina. A linguagem literária de Barros apresenta uma visão de mundo em conformidade com o segmento sociocultural, Pantanal, e com as motivações inconscientes que a ela se impõem, que transforma a razão em emoção, a beleza em novidade poética, e serve-se da imagem surreal das palavras para metaforizar sentimentos, comportamentos e fatos da vida para representar o homem que se aniquila diante a práticas culturais e acaba por abandonar seus aspectos mais primitivos. As metáforas visuais de Brunna modelam a identidade psicológica e sociocultural da mulher e suscitam uma incursão na imagem Deusa, a Grande Mãe. Vê-se que a configuração materna da personagem é construída em bases arquetípicas - um modelo inconsciente registrado na psique imemorial e projetado de forma própria nessa figura ficcional.

\section{Em busca das (in) completudes}

A linguagem é vista como uma forma de interação humana. Interagir por meio da linguagem é se comunicar levando em consideração o contexto enunciativo que permeiam este meio. Isso é possível, pois a base da interação é o (inter) discurso. No contexto pós-moderno, o questionamento do caráter de verdade e objetividade em diversos campos do saber repercutem na literatura e nas teorias literárias, possibilitando um novo olhar sobre as manifestações culturais.

Ao propor o diálogo entre literatura e ilustração e levantar questionamentos acerca dos limites e possibilidades da linguagem ficcional, levamos em consideração as palavras de

Anu. Lit., Florianópolis, v. 23, n. 2, p. 34-45, 2018. ISSNe 2175-7917 
Barthes. Segundo o autor, "não existe por trás do texto ninguém ativo (o escritor) e diante dele ninguém passivo (o leitor); não há um sujeito e um objeto" (BARTHES, 2002, p. 23). Assim, partindo do desenho da artista e da exposição do jogo ficcional de Manoel de Barros, os leitores são postos em movimento para assumir uma postura criadora e questionadora quanto ao poder e limites da criação estética. Essa compreensão advém da necessidade que sentimos de não prendermos o nosso aporte teórico somente aos efeitos técnicos de cada arte, mas também aos processos socioculturais que possibilitaram a sua produção. A obra em processo sempre é incompleta, inacabada, mesmo quando é publicada; o trabalho do artista é motivado justamente pela busca dessa completude.

\section{Referências}

AZEVEDO, Lucy Ferreira. Paixões e identidade cultural em Manoel de Barros: o poema como argumento. Londrina: Unopar, 2015.

BARROS, Manoel de. Poesia completa. São Paulo: Leya, 2010.

BARTHES, Roland. Elementos de semiologia. São Paulo: Cultrix, 2002.

BENJAMIN, Walter. A obra de arte na época de sua reprodutibilidade técnica. In: ADORNO, Theodor et al. Teoria da Cultura de massa. São Paulo: Paz e Terra, 1982. p. 205-240.

BLACK, Max. Metaphor. In: Models and metaphors: studies in language and philosophy. Ithaca, NY: Cornell University Press, 1962, p. 25-47.

BRITTO, Paulo Henrique. Trovar claro. São Paulo: Companhia das Letras, 1997.

CANCLINI, Nestor Garcia. Consumidores e cidadãos: conflitos multiculturais da globalização. Rio de Janeiro: UFRJ, 1995.

CARVALHO, Julia. Uma personagem diferente e sua representação na literatura infantil. 2014. 101 f. Dissertação (Mestrado) - Curso de Artes \& Design, PUC/Rio, Rio de Janeiro, 2014.

CARVALHAL, Tânia Franco (Org.). Literatura comparada no mundo: questões e métodos. Porto Alegre: L\&PM, 1997.

CHEVALIER, Jean; GHEERBRANT, Alain. Dicionário de Símbolos. Rio de Janeiro: José. Olympio, 1998.

COUTINHO, Eduardo. Literatura Comparada, literaturas nacionais e questionamento do cânon. Revista Brasileira de Literatura Comparada. Rio de Janeiro, n. 3, p. 67-73, 1996.

DERRIDA, Jacques. A escritura e a diferença. Trad. de Narua Beatriz Marques Nizza da Silva. 2.ed. São Paulo: Perspectiva, 1995.

DIAS, Maria Heloísa Martins. Espaço e linguagem na poesia de Manoel de Barros. Antares: letras e humanidades. Caxias do Sul, n. 1, p. 125-133, 2009. Disponível em: http://www.ucs.br/etc/revistas/index.php/antares/article/viewFile/304/264. Acesso em: $10 / 01 / 2008$. 
DINIZ, Luis de Melo. O processo de interdiscursividade entre as artes: literatura e cinema. Graphos. João Pessoa, v. 9, n. 1, p. 89-102, jan./jul.2007.

FISCHER, Ernst. A Necessidade da Arte. Rio de Janeiro: Zahar, 1983.

FRYE, Northrop. Anatomia da Crítica. São Paulo, Cultrix, 2000.

LIMA, Marinei Almeida. Entre voos, pântanos e ilhas: um estudo comparado entre Manoel de Barros e Eduardo White. 2008. 215 f. Tese (Doutorado) - Curso de Literatura Brasileira, Faculdade de Filosofia, Letras e Ciências Humanas. USP, São Paulo, 2008.

MANCUSO, Bruna. As ilustrações de Brunna Mancuso mostram a força feminina com formas geométricas e botânica: Entrevista. 2016. Disponível em: http://www.zupi.com.br/ilustracoesde-brunna-mancuso-mostram-forca-feminina-com-formas-geometricas-e-botanica. Disponível

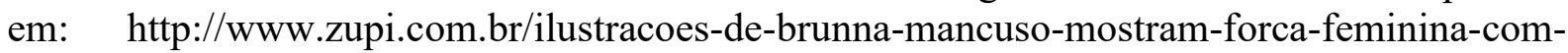
formas-geometricas-e-botanica/. Acesso em: 07/09/2018.

MILNER, Andrew. Literature, Culture and Society. New York: New York U P, 1996.

NITRINI, Sandra. Literatura Comparada: história, teoria e crítica. São Paulo: EDUSP, 1997.

OLIVEIRA, Marinyze das Graças Prates de. E a tela invade a página: laços entre literatura e cinema em João Gilberto Noll. 1996. 200 f. Dissertação (Mestrado) - Pós-Graduação em Cultura e Sociedade do IHAC/UFBA, UFBA, Salvador, 1996.

PRAZ, Mario. Literatura e Artes Visuais. Trad. de J. P. Paes. São Paulo: Cultrix; USP 1982.

PUCHEU, ALBERTO. Manoel de Barros: em que acreditar senão no riso? Estud. Av. [on-line]. 2015 , v. 29, n. 85, p. 281-293. Disponível em: http://dx.doi.org/10.1590/S010340142015008500018. Acesso em: 13/01/2018.

SILVEIRA, Ênio. Sempre novo alquimista do verbo. In: BARROS, Manoel de. Livro das Ignorãças. 10.ed. Rio de Janeiro: Record, 2001, p. 143-147.

SUTTANA, Renato N. Uma poética do deslimite: o poema como imagem na obra de Manoel de Barros. 0995. 200 f. Dissertação (Mestrado) - Curso de Mestrado em Literaturas de Língua Portuguesa, Pontifícia Universidade Católica de Minas Gerais, Belo Horizonte, 1995.

WOOLGER, Jennifer Barker. WOOLGER, Roger J.. A deusa interior. Tradução de Carlos Afonso Malferrari. São Paulo: Cultrix, 1994.

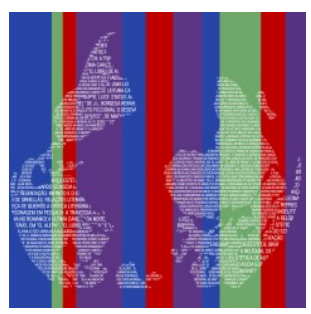

